\title{
ARTIGOS \\ EVOLUÇÃO E CONCENTRAÇÃO INTER-REGIONAL E INTRARREGIONAL DA PRODUÇÃO DE LEITE: O CASO DO ESTADO DE SANTA CATARINA NO PERÍODO DE 2000 A 2012
}

\author{
Duarte $\mathrm{VN}^{*}$, Cavalcanti $\mathrm{KA}^{* *}$
}

\section{Resumo}

Neste artigo teve-se como objetivo mostrar a evolução da produção de leite no Estado de Santa Catarina de 2000 a 2012, bem como a existência ou não de concentração inter-regional e intrarregional da produção. O estudo foi realizado por meio da descrição do comportamento da produção leiteira de todas as mesorregiões e microrregiões geográficas catarinenses. A concentração da produção foi encontrada pela aplicação do índice Herfindahl-Hirschamn para medir a participação anual, tanto de cada mesorregião na produção estadual quanto de cada microrregião na produção da respectiva mesorregião. Os resultados mostram que a mesorregião Oeste Catarinense é a maior produtora de leite, tendo participado com 74\% da produção total do Estado em 2012; mostram, também, a ocorrência de concentração inter-regional da produção estadual, influenciada, principalmente, pela produção do Oeste, que cresceu a taxas superiores às das demais mesorregiões. Quanto à questão intrarregional, percebe-se ter havido períodos de concentração e desconcentração da produção, com a mesorregião Oeste Catarinense apresentando maior regularidade quanto à participação de suas microrregiões na produção total da mesorregião. Por fim, conclui-se que a mesorregião Oeste, além de ser a maior produtora estadual de leite, também foi a que registrou o maior crescimento da produção no período, $233 \%$. Conclui-se, ainda, que a tendência de

\footnotetext{
* Mestre em Engenharia de Produção pela Universidade Federal de Santa Catarina; Graduado em Ciências Econômicas pela Universidade do Oeste de Santa Catarina; BR 463 - Km 4,5, 79906-000, Ponta Porã, Mato Grosso do Sul; vilmarufms@yahoo.com.br

** Graduanda em Ciências Econômicas pela Universidade Estadual de Mato Grosso do Sul; karol-cavalcanti@hotmail.com
} 
concentração da produção se mostrou tanto em nível inter-regional quanto intrarregional; a tendência de desconcentração intrarregional também foi evidenciada.

Palavras-chave: Produção de leite. Mesorregiões geográficas. Microrregiões geográficas. Concentração. Santa Catarina.

\title{
Evolution, inter-regional and intrarregional concentration of milk production: the case of Santa Catarina State from 2000 to 2012
}

\begin{abstract}
In this article it was aimed to show the development of milk production in the state of Santa Catarina from 2000 to 2012, and the existence of inter-regional and intrarregional concentration of production. The study was carried out by describing the behavior of milk production of all geographic mesoregions and microregions of the state. The concentration of production was found by applying the HerfindahlHirschamn index to measure the annual contribution both of each mesoregion in the state production, and of each microregion in the production of its mesoregion. The results show that the mesoregion West of Santa Catarina is the largest producer of milk, participating with $74 \%$ of the total state production in 2012; they also show the occurrence of inter-regional concentration of state production, influenced mainly by Western production, which grew at higher rates than the other mesoregions. As for intrarregional issue, we can see that there have been periods of concentration and decentralization of production, with the mesoregion West of Santa Catarina submitting more regularly on the participation of its microregions in the total production of the mesoregion. Finally, it is concluded that the West mesoregion, besides being the largest state milk producer, it was also the one which recorded the highest growth of production in the period, 233\%. It is also concluded that the trend of concentration of the production was showed both in inter-regional and intrarregional levels; the trend of intrarregional decentralization was also highlighted. Keywords: Milk production. Geographic mesoregions. Geographic microregions. Concentration. Santa Catarina.
\end{abstract}

\section{INTRODUÇÃO}

A produção de leite no Brasil foi de 32,3 bilhões de litros em 2012, sendo 80,4\% desse volume produzidos pelos sete principais estados produtores. Minas Gerais se apresenta como o maior produtor nacional, com produção de 8,9 bilhões de litros, seguido pelos Estados do Rio Grande do Sul, com 4 bilhões, Paraná, com 3,9 bilhões, e Goiás, com 3,5 bilhões. O crescimento da produção leiteira nacional de 2000 a 2012 foi de 63,4\%, com o Estado de Santa Catarina apresentando a maior taxa de crescimento entre os principais produtores, 170,9\%, seguido pelo Paraná, com 120,5\%. ${ }^{1}$

Santa Catarina, objeto do presente estudo, apresenta-se como o quinto maior produtor nacional de leite, com 2,7 bilhões de litros produzidos em 2012. Localizado no Sul do País, o Estado está dividido em seis mesorregiões, com o Oeste Catarinense se apresentando como o maior produtor 
estadual de leite, com 2 bilhões de litros produzidos nesse mesmo ano, seguido pelas mesorregiões Vale do Itajaí e Sul Catarinense, com 236,4 milhões e 180,6 milhões de litros, respectivamente. A mesorregião Oeste também foi a que mais expandiu sua produção no período de 2000 a 2012 (233\%). ${ }^{1}$

Assim, percebe-se ter havido uma intensa concentração da produção nacional de leite em poucos estados; o mesmo acontece com o Estado de Santa Catarina, com a mesorregião Oeste concentrando 74\% da produção em 2012, como mostrado na Tabela 1. Nesse sentido, passa a ser de suma importância entender se existe tendência de aumento dessa concentração ou se a desconcentração regional é uma questão de tempo. Além disso, passa a ser importante, também, entender se essa concentração se repete internamente nas mesorregiões produtoras, ou seja, se há tendência de concentração intrarregional, em razão das peculiaridades inerentes a cada bacia leiteira.

Diante desse contexto, no presente trabalho teve-se como objetivo mostrar a evolução da produção de leite no Estado de Santa Catarina no período de 2000 a 2012, buscando identificar a existência ou não de concentração inter-regional e intrarregional da produção. O estudo foi desenvolvido com base em uma pesquisa bibliográfica e descritiva, elaborada a partir de material já publicado. Os dados foram obtidos na Síntese Anual da Agricultura de Santa Catarina, os quais são publicados anualmente pela Empresa de Pesquisa Agropecuária e Extensão Rural de Santa Catarina (Epagri) e pelo Centro de Socioeconomia e Planejamento Agrícola (Cepa).

$\mathrm{O}$ artigo está dividido em cinco seções. Além desta seção introdutória, a segunda seção apresenta os sistemas de produção de leite predominantes no Brasil, e a terceira ressalta os aspectos metodológicos utilizados para o desenvolvimento do trabalho. Na sequência, a quarta seção apresenta os resultados da pesquisa, no que se refere à evolução da produção tanto das meso quanto das microrregiões, bem como a ocorrência de concentração e/ou desconcentração inter e intrarregional da produção estadual. Por fim, na quinta seção são apresentadas as considerações finais.

\section{SISTEMAS DE PRODUÇÃO DE LEITE PREDOMINANTES NO BRASIL}

O agronegócio do leite e seus derivados desempenha um papel de suma importância no suprimento de alimentos e geração de emprego e renda para uma parte significativa da população rural brasileira. A produção primária de leite está disseminada em quase todo o território nacional, contribuindo de maneira decisiva para a manutenção do produtor no campo e, consequentemente, para a redução do êxodo rural, já que é um dos poucos produtos agropecuários que propicia uma renda mensal ao produtor. Os sistemas de produção em uso são bastante diferenciados entre as regiões, havendo sistemas inadequados em grande parte destas, o que resulta em baixa produtividade do rebanho e dos demais recursos envolvidos na exploração.

São quatro os tipos de sistemas de produção de leite predominantes no Brasil, a saber: 
a) sistema extensivo, que envolve vacas com até 1.200 litros/ano, criadas exclusivamente a pasto;

b) sistema semiextensivo, que contempla vacas com produção anual entre 1.200 e 2.000 litros, criadas a pasto, com suplementação volumosa em épocas de escassez deste;

c) sistema intensivo a pasto, que agrega vacas com produção entre 2.000 e 4.500 litros/ano, criadas a pasto com forragens de alta capacidade de suporte, com suplementação volumosa em alguns meses do ano e, em alguns casos, durante o ano inteiro;

d) sistema intensivo em confinamento, que abrange vacas com produção acima de 4.500 litros/ano, mantidas confinadas e alimentadas no cocho com forragens conservadas, como silagens e fenos. ${ }^{2}$

O maior desafio desses sistemas é reduzir os custos de produção e aumentar a produtividade por animal e/ou da terra, de acordo com as características da região. Os sistemas a pasto aparecem como os mais viáveis em termos econômicos, porém, apresentam uma complexidade maior em relação às interferências climáticas, às pragas e às doenças na produção de forragens. ${ }^{3} \mathrm{O}$ conceito-chave nesses sistemas é a substituição de combustível, máquinas e equipamentos por vacas, no processo de colheita da forragem. Além disso, os investimentos na propriedade com instalações para abrigar animais e maquinários são menores em comparação com os sistemas em confinamento. Embora as receitas do sistema de produção a pasto sejam inferiores às do sistema confinado, as margens de lucro têm sido mais elevadas. ${ }^{4,5,6 .}$

O sistema em confinamento, embora apresente maior produtividade, eleva o custo de produção, em decorrência do uso intensivo de grãos e outros suplementos na alimentação dos animais. Porém, em alguns casos, esse sistema se torna a melhor alternativa de produção, principalmente para aqueles produtores cujas propriedades dispõem de poucas áreas apropriadas para o cultivo de pastagens ou, então, estão inseridas no meio urbano. Nesse caso, deve-se considerar que os transtornos gerados pelo acúmulo de dejetos oriundos de rebanhos confinados e os elevados custos de manejo e distribuição deles se constituem em sérios problemas para os países ou regiões que adotam esses sistemas de produção.

A escolha do sistema de produção adequado tem sido de suma importância no ramo leiteiro, por possibilitar a elevação das receitas da atividade. A principal preocupação dos produtores deve ser com o aumento dos lucros, o que somente é possível por meio da otimização dos recursos disponíveis, com manejos adequados dos solos, das pastagens e dos animais. Assim, os produtores que fizerem uso de tecnologias que permitam a redução dos custos de produção terão maiores possibilidades de permanecer na atividade. ${ }^{7}$

A possibilidade de integração entre lavoura e pecuária também pode ser definida como um sistema de produção, uma vez que a produção animal pode estar associada à produção de grãos, por meio da alternância com a produção de forragens no mesmo ano agrícola. ${ }^{8} \mathrm{Em}$ algumas regiões do País, como é o caso da região Sul, pelas suas extensas áreas agricultáveis, onde se concentra boa parte 
da produção nacional de grãos, com a rotação de culturas constituindo uma necessidade de manejo das áreas agrícolas, a integração das atividades lavoura-pecuária leiteira pode se transformar em uma rara oportunidade para a otimização do uso dos recursos envolvidos nas explorações. ${ }^{9}$

Além dos diferentes sistemas de produção observados, deve-se considerar também a existência de dois tipos de produtores: os especializados, que têm a produção leiteira como atividade principal, obtida a partir de rebanhos especializados, além de outros ativos específicos para tal fim, e os não especializados, para os quais o leite nada mais é do que um subproduto do bezerro de corte, que encontram no leite uma atividade típica de subsistência e de complementação da renda, sendo eles os principais responsáveis pela formação de excedentes de leite de baixa qualidade na época das chuvas. ${ }^{10}$

Os produtores ainda podem ser classificados como comerciais e não comerciais, a partir da venda ou não dos excedentes produtivos. Os produtores comerciais, a exemplo dos especializados, trabalham com estruturas produtivas que lhes permitem gerar excedentes, enquanto os não comerciais, assim como os não especializados, dispõem de tecnologias extremamente rudimentares, produzindo apenas para o autoconsumo. ${ }^{11}$

De qualquer forma, sejam eles produtores especializados ou comerciais, sejam não especializados ou não comerciais, a verdade é que estão presentes em todas as regiões produtoras de leite do País, o que nos permite uma noção bastante clara e real de como são constituídos os diferentes sistemas produtivos que formam o segmento de produção primária de leite no Brasil.

\section{MATERIAL E MÉTODOS}

O estudo foi realizado com base em uma pesquisa bibliográfica e descritiva, elaborada a partir de material já publicado, por meio da qual se tem o objetivo de descrever as características de determinada população ou fenômeno ou, então, o estabelecimento de relação entre as variáveis estudadas. Neste caso, os dados são obtidos de fontes constituídas, principalmente, por livros e trabalhos científicos e técnicos, os quais são disponibilizados com a finalidade explícita de serem lidos. Trata-se de uma investigação em que não há interferência do pesquisador, o qual apenas procura entender a frequência com que determinados fenômenos ocorrem. ${ }^{12}$

Assim, inicialmente, identificou-se a participação de cada mesorregião na produção total de leite do Estado, mostrando a evolução da produção de cada uma delas de 2000 a 2012. Na sequência, identificou-se a participação de cada microrregião na produção total da respectiva mesorregião, bem como a evolução da produção de cada microrregião no período. Dessa forma, foi possível verificar tanto o comportamento da produção de cada mesorregião em relação às outras mesorregiões quanto o comportamento de cada microrregião em relação às demais microrregiões e, ao mesmo tempo, em relação a sua própria mesorregião.

A concentração da produção de leite no Estado foi medida por intermédio da aplicação do índice de Herfindahl-Hirschman, que expressa o grau de concentração de um dado conjunto de ele- 
mentos, podendo ser usado para medir a concentração da produção de um grupo de empresas de um dado setor ou de um conjunto de empresas de um país, estado ou município. Especificamente para este trabalho, o índice de Herfindahl-Hirschman foi utilizado para medir a concentração inter e intrarregional. No primeiro caso, o índice foi calculado pela somatória do quadrado da participação de cada mesorregião sobre a produção total do Estado. Da mesma forma, para medir a concentração intrarregional, o índice foi calculado pela somatória do quadrado da participação de cada microrregião sobre a produção da respectiva mesorregião, para cada ano analisado.

As informações sobre a produção de leite foram obtidas a partir de dados da Síntese Anual da Agricultura de Santa Catarina no período de 2000 a 2012, edições de 2005-2006, 2010-2011, 2012 2013 e 2013-2014, publicadas pela Empresa de Pesquisa Agropecuária e Extensão Rural de Santa Catarina (Epagri) em conjunto com o Centro de Socioeconomia e Planejamento Agrícola (Cepa).

\section{RESULTADOS E DISCUSSÃO}

A Tabela 1 mostra a evolução da produção de leite nas mesorregiões e microrregiões do Estado de Santa Catarina de 2000 a 2012. Os dados mostram que a produção estadual cresceu 170,9\% no período. A mesorregião Oeste apresenta-se como a maior produtora do Estado, tendo sido responsável pela produção de cerca de 2 bilhões de litros em 2012, ou seja, 74\% da produção total. Na sequência aparecem as mesorregiões do Vale do Itajaí, Sul Catarinense, Serrana, Norte Catarinense e da Grande Florianópolis, com $8,7 \%, 6,6 \%, 5,5 \%, 3 \%$ e 2,1\%, respectivamente.

A mesorregião Oeste também foi a que apresentou a maior expansão da produção de leite no período de 2000 a 2012, 233\%. Todas as microrregiões que a compõem apresentaram aumento da produção, mas a de Chapecó foi a que mais contribuiu para esse crescimento, tendo expandido sua produção em 315\% no período. Por outro lado, a que menos cresceu foi a de Joaçaba, 60,5\%, passando de 93,3 milhões de litros, em 2000, para próximo de 150 milhões, em 2012. Esse desempenho do Oeste está relacionado à concentração de agroindústrias leiteiras na região, o que tem aumentado a concorrência pela matéria-prima, resultando em maior preço pago ao produtor e aumento da produção regional. ${ }^{1}$ 
Tabela 1 - Produção de leite nas mesorregiões e microrregiões geográficas de Santa Catarina de 2000 a 2012 (mil litros)

\begin{tabular}{|c|c|c|c|c|c|}
\hline Meso e Microrregião & 2000 & 2003 & 2006 & 2009 & 2012 \\
\hline Oeste Catarinense & 602.807 & 909.605 & 1.241 .171 & 1.618 .968 & 2.007 .685 \\
\hline Chapecó & 167.552 & 288.876 & 405.082 & 598.977 & 695.382 \\
\hline Concórdia & 103.500 & 148.189 & 202.652 & 239.810 & 349.459 \\
\hline Joaçaba & 93.362 & 99.661 & 113.142 & 137.578 & 149.854 \\
\hline São Miguel do Oeste & 174.002 & 270.567 & 365.915 & 424.207 & 558.943 \\
\hline Xanxerê & 64.391 & 102.312 & 154.380 & 218.396 & 254.047 \\
\hline Norte Catarinense & 74.051 & 72.616 & 69.236 & 81.588 & 83.860 \\
\hline Canoinhas & 46.320 & 47.268 & 46.320 & 47.930 & 54.471 \\
\hline Joinville & 22.512 & 19.765 & 17.698 & 28.131 & 23.433 \\
\hline São Bento do Sul & 5.219 & 5.583 & 5.218 & 5.527 & 5.956 \\
\hline Serrana & 54.171 & 56.245 & 59.696 & 100.445 & 150.460 \\
\hline Campos de Lages & 40.505 & 41.497 & 42.530 & 66.186 & 113.769 \\
\hline Curitibanos & 13.666 & 14.748 & 17.166 & 34.259 & 36.691 \\
\hline Vale do Itajaí & 160.141 & 162.951 & 193.744 & 205.579 & 236.450 \\
\hline Blumenau & 40.701 & 34.821 & 31.730 & 30.742 & 29.388 \\
\hline Itajaí & 8.870 & 11.014 & 8.903 & 8.684 & 37.958 \\
\hline Ituporanga & 26.205 & 29.189 & 38.831 & 45.918 & 53.023 \\
\hline Rio do Sul & 84.365 & 87.927 & 114.280 & 120.235 & 116.081 \\
\hline Grande Florianópolis & 32.434 & 45.406 & 43.675 & 52.206 & 58.556 \\
\hline Florianópolis & 7.935 & 10.382 & 10.309 & 20.514 & 22.892 \\
\hline Tabuleiro & 15.196 & 26.395 & 23.612 & 16.265 & 19.130 \\
\hline Tijucas & 9.303 & 8.629 & 9.754 & 15.427 & 16.534 \\
\hline Sul Catarinense & 79.493 & 85.463 & 102.289 & 179.014 & 180.640 \\
\hline Araranguá & 11.585 & 11.376 & 10.412 & 4.318 & 7.035 \\
\hline Criciúma & 17.629 & 16.747 & 22.345 & 27.635 & 28.113 \\
\hline Tubarão & 50.279 & 57.340 & 69.532 & 147.061 & 145.492 \\
\hline Santa Catarina & 1.003 .098 & 1.332 .286 & 1.709 .811 & 2.237 .800 & 2.717 .651 \\
\hline
\end{tabular}

Fonte: Empresa de Pesquisa Agropecuária e Extensão Rural de Santa Catarina/Centro de Socioeconomia e Planejamento Agrícola. ${ }^{1}$

A mesorregião Norte Catarinense está entre as menos expressivas na produção estadual de leite, ocupando a $5^{\mathrm{a}}$ colocação, à frente apenas da mesorregião da Grande Florianópolis. Composta por três microrregiões, apresentou um crescimento de apenas 13,2\% na produção de 2000 a 2012. Embora a produção regional tenha se expandido, observa-se que a microrregião de São Bento do Sul manteve certa estabilidade no volume produtivo no período, enquanto a de Joinville apresentou redução de 2000 até 2006, cresceu de 2006 para 2009, e de 2009 para 2012, sua produção voltou a cair em 16,7\%. Em relação à microrregião de Canoinhas, esta teve sua produção leiteira expandida em 17,6\% no período. De 2011 para 2012, a produção da mesorregião Norte cresceu abaixo da média estadual, o que se explica pela estiagem ocorrida nos meses de agosto e setembro em todo o Estado, que prejudicou o desenvolvimento das pastagens de inverno em algumas regiões. ${ }^{1}$

A mesorregião Serrana é a $4^{a}$ no ranking das mais expressivas na produção de leite em Santa Catarina; composta por duas microrregiões, Campos de Lages e Curitibanos, apresentou crescimento produtivo de $177,7 \%$ no período em análise. A microrregião dos Campos de Lages é a mais representativa na mesorregião, tendo respondido por 75,6\% da produção regional de leite em 2012 . O crescimento da produção dessas microrregiões também foi expressivo no período, $180,9 \%$ para a micror- 
região dos Campos de Lages e 168,5\% para a microrregião de Curitibanos. A mesorregião Serrana foi a única que apresentou redução da produção em 2012 em relação ao ano anterior, onde as questões climáticas já mencionadas acima foram determinantes para a queda da produção. ${ }^{1}$

Como a segunda maior produtora de leite do Estado aparece a mesorregião do Vale do Itajaí. Integram essa mesorregião as microrregiões de Blumenau, Itajaí, Ituporanga e Rio do Sul. A mesorregião apresentou evolução positiva de $47,6 \%$ na produção de leite de 2000 a 2012. A microrregião de Rio do Sul é a maior produtora, sua participação na produção regional foi de $49 \%$ em 2012. A microrregião de Blumenau foi a única a apresentar redução de participação na produção regional de leite no período em questão. De uma participação de 25,4\%, em 2000, passou a representar apenas 12,4\%, em 2012.

A mesorregião da Grande Florianópolis aparece em último lugar em termos de participação na produção leiteira do Estado, com apenas 2,1\%. Sua produção apresentou crescimento de 80,5\% no período analisado. A microrregião de Florianópolis participou com 39\% da produção total da mesorregião em 2012, contra 32,7\% da microrregião de Tabuleiro e 28,2\% da microrregião de Tijucas. A microrregião de Florianópolis foi a que mais expandiu sua produção no período, 188,5\%. Já a microrregião de Tijucas aumentou em 77,7\%, e a de Tabuleiro, em 25,9\%.

Na terceira posição em termos de participação na produção leiteria estadual aparece a mesorregião Sul Catarinense, a qual expandiu sua produção em 127,2\% de 2000 a 2012. Composta por três microrregiões, Araranguá, Criciúma e Tubarão, tem a microrregião de Tubarão como a maior produtora, a qual respondeu por 80,5\% da produção regional em 2012. Tanto a microrregião de Tubarão quanto a de Criciúma tiveram aumento de produção no período. Já a microrregião de Araranguá apresentou queda, passando de 11,5 milhões de litros, em 2000, para 7 milhões, em 2012. Em 2009 a produção dessa microrregião foi de apenas 4,3 milhões de litros. O desempenho da mesorregião Sul Catarinense no período em análise pode estar relacionado ao preço do leite pago ao produtor, uma vez que o preço médio regional está entre os mais altos do Estado. ${ }^{1}$

\subsection{CONCENTRAÇÃO INTER-REGIONAL DA PRODUÇÃO}

A Figura 1 mostra o nível de concentração inter-regional da produção leiteira estadual no período de 2000 a 2012. Ao se aplicar o Índice de Herfindahl-Hirschman para avaliar o comportamento da produção quanto à participação de cada mesorregião na produção total do Estado, observa-se ter havido uma tendência de concentração cada vez maior em todo o período estudado, impulsionada, principalmente, pelo aumento da produção no Oeste Catarinense. Percebe-se que nos primeiros anos do período em análise, mais precisamente de 2000 a 2003, a concentração se acentuou em razão de um aumento de produção nessa mesorregião de 306,8 milhões de litros (Tabela 1). A partir de então, a concentração continuou aumentando, embora em proporções menores, até ao ano 2006, mantendo-se estável de 2006 a 2011, voltando a aumentar de 2011 a 2012. 


\section{Santa Catarina}

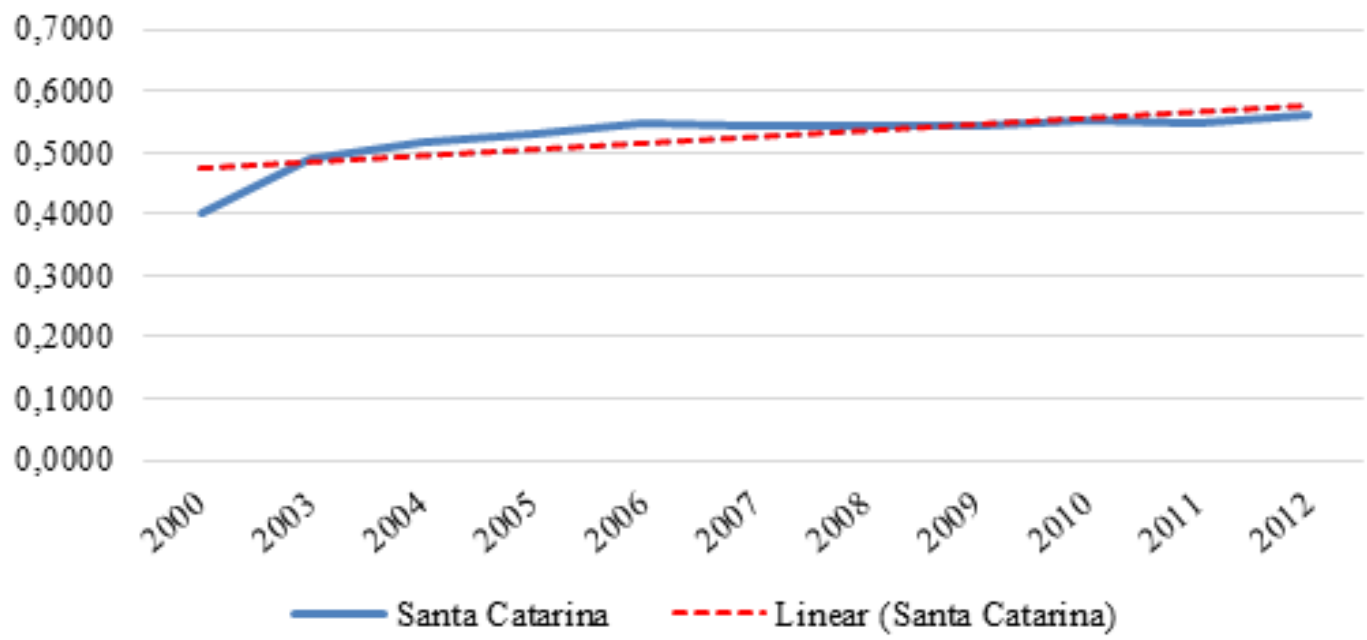

Figura 1 - Concentração inter-regional da produção de leite em Santa Catarina de 2000 a 2012

No decorrer de 2011 para 2012, o aumento de produção na mesorregião Oeste foi de 161 milhões de litros, e de 2010 para 2012, a expansão foi de 265,4 milhões. ${ }^{1}$ Além do Oeste Catarinense, outras mesorregiões também apresentaram aumentos expressivos na produção em alguns períodos, como é o caso, por exemplo, da mesorregião Sul Catarinense, que expandiu sua produção em 75\% de 2006 a 2009, e da mesorregião Serrana, cujo aumento foi de 152\% de 2006 a 2012 (Tabela 1), o que não impediu o aumento da concentração da produção estadual no período estudado, em decorrência da influência da mesorregião Oeste.

\subsection{CONCENTRAÇÃO INTRARREGIONAL DA PRODUÇÃO}

A Figura 2 mostra o nível de concentração dentro das mesorregiões, ou seja, a participação da produção anual de cada microrregião que integra as mesorregiões estudadas. Assim, observa-se que a mesorregião Oeste Catarinense manteve certa estabilidade ao longo do período em questão, significando, em outras palavras, que a produção de suas respectivas microrregiões cresceu em proporções bastante semelhantes.

A referida Figura mostra, também, que a mesorregião Norte Catarinense apresentou uma tendência de concentração de 2000 a 2006, que se acentuou em 2007, em razão do aumento da participação da microrregião de Canoinhas e queda na de Joinville. De 2007 a 2009 houve uma pequena desconcentração, que ocorreu mediante o aumento da produção da microrregião de Joinville. De 2009 a 2012 percebe-se novamente uma ligeira tendência de concentração na mesorregião, que ocorreu por ocasião de aumento na produção da microrregião de Canoinhas, que cresceu 13,6\%, e nova queda na de Joinville, cuja produção se reduziu em 16,7\% nesses três anos, conforme mostrado na Tabela 1. 


\section{Santa Catarina}

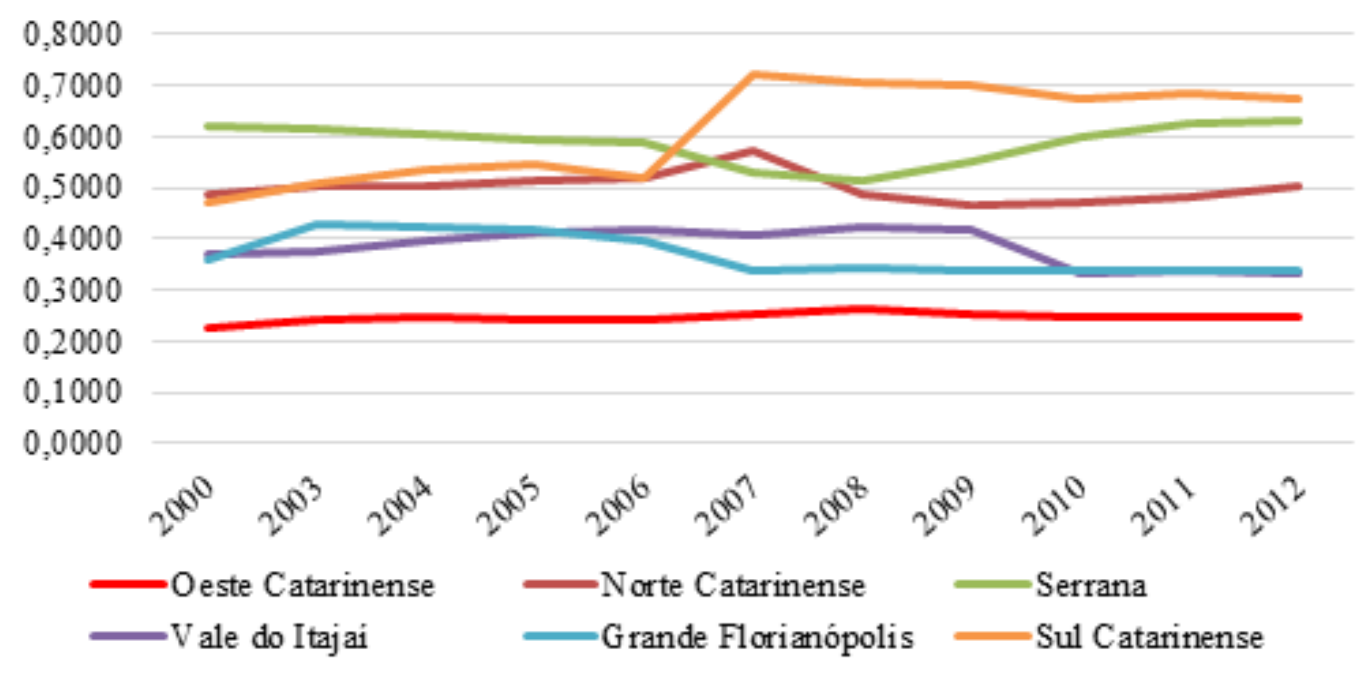

Figura 2 - Concentração intrarregional da produção de leite em Santa Catarina de 2000 a 2012

Quanto à mesorregião Serrana, na Figura 2 é possível observar que esta apresentou desconcentração da produção de 2000 a 2008, que ocorreu mediante o baixo crescimento da produção da microrregião dos Campos de Lages, maior produtora, e aumento mais que proporcional na produção da microrregião de Curitibanos. De 2008 a 2012, percebe-se que a concentração aumentou na mesorregião, impulsionada pelo expressivo aumento da produção da microrregião dos Campos de Lages.

Em relação à mesorregião do Vale do Itajaí, observa-se uma ligeira concentração da produção de 2000 a 2006, com consequente estabilidade de 2006 a 2009. De 2009 a 2010, percebe-se uma rápida desconcentração produtiva, decorrente do aumento da produção na microrregião de Itajaí, que mostrou expressiva expansão, e de redução na microrregião de Rio do Sul, maior produtora regional, cuja produção foi reduzida em 10,06\% (Tabela 1). De 2010 a 2012, a participação de cada microrregião em relação à produção total da mesorregião se manteve estável.

A mesorregião da Grande Florianópolis, por conseguinte, apresentou concentração da produção no período de 2000 a 2003, decorrente do expressivo aumento da produção da microrregião de Tabuleiro, maior produtora da mesorregião. De 2003 a 2006, observa-se ligeira desconcentração produtiva, que se acentuou de 2006 a 2007. Por outro lado, de 2007 a 2012, a participação das microrregiões na produção regional foi pautada pela estabilidade.

No que diz respeito à mesorregião Sul Catarinense, pode-se observar que de 2000 a 2005 a produção tendeu a se concentrar, com pequena inversão de 2005 a 2006. De 2006 a 2007, a concentração se acentuou de forma expressiva, em razão do crescimento da produção da microrregião de Tubarão, maior produtora da mesorregião, e da redução significativa da produção da microrregião de Araranguá. De 2007 a 2012 percebe-se ter havido uma ligeira tendência de desconcentração da produção leiteira na mesorregião. 


\section{CONCLUSÃO}

A pesquisa demonstra que a mesorregião Oeste Catarinense é a maior produtora estadual de leite, tendo sido responsável por 2 bilhões dos 2,7 bilhões de litros produzidos em 2012, o que representa uma participação regional de cerca de $74 \%$ da produção total do Estado. Em segundo lugar aparece a mesorregião do Vale do Itajaí, cuja produção representou 8,7\% do total estadual em 2012. Todas as mesorregiões apresentaram crescimento da produção no período em análise, com destaque para a mesorregião Oeste, onde a expansão foi de $233 \%$. A mesorregião Norte Catarinense foi a que apresentou o menor crescimento no período estudado, de apenas 13,2\%.

Os resultados mostram tendência em direção à concentração inter-regional da produção leiteira de 2000 a 2012, impulsionada, principalmente, pelo aumento da produção no Oeste Catarinense, que cresceu a taxas superiores às verificadas nas demais mesorregiões. Todas as microrregiões que compõem a mesorregião Oeste apresentaram aumento de produção no período, com destaque para as microrregiões de Chapecó, cuja produção cresceu 315\%, e de São Miguel do Oeste, com crescimento de $221,2 \%$.

Em relação à distribuição intrarregional da produção, ou seja, como esta está distribuída entre as microrregiões, percebe-se que o Oeste Catarinense apresentou maior regularidade quanto à participação de suas respectivas microrregiões na produção total da mesorregião. Já nas demais mesorregiões, observa-se a existência de períodos em que prevaleceu a tendência de concentração e outros em que a desconcentração ficou mais evidente. Esse comportamento da produção é resultado de peculiaridades inerentes ao interior do Estado catarinense, como é o caso do clima, por exemplo.

De qualquer forma, faz-se necessário ressaltar que a tendência de concentração da produção ao longo do período estudado se mostrou tanto em nível inter-regional, em razão do crescimento da produção no Oeste Catarinense, quanto intrarregional em decorrência das variações na produção das microrregiões que compõem as mesorregiões, caso da mesorregião Sul Catarinense, que apresentou tendência de concentração. A tendência de desconcentração intrarregional da produção também foi evidenciada, sendo este o caso da mesorregião da Grande Florianópolis.

Os preços mais elevados pagos aos produtores são registrados na microrregião de Chapecó (Oeste Catarinense) e na mesorregião Sul do Estado. A diferença de preços é decorrente da maior concorrência entre as indústrias para a aquisição da matéria-prima e da qualidade desta, principalmente no que se refere à concentração de sólidos (gordura e proteína). Além disso, o fato de as indústrias se concentrarem na zona de produção permite que elas paguem um preço mais alto, em razão da redução do custo do frete. ${ }^{1}$ Juntando-se a isso, os problemas climáticos, como o inverno rigoroso que faz no Sul do País e as estiagens que atingem Santa Catarina em algumas estações do ano, explicam o panorama da produção leiteira catarinense no período em análise. 


\section{REFERÊNCIAS}

1. Empresa de Pesquisa Agropecuária e Extensão Rural de Santa Catarina/Centro de Socioeconomia e Planejamento Agrícola. Síntese anual da agricultura de Santa Catarina 2005-2006, 20102011, 2012-2013 e 2013-2014. [acesso em 2015 mar 15]. Disponível em: http://www.epagri.sc.gov. $\underline{\mathrm{br} / \text { ?page } \mathrm{id}=3210}$

2. Assis AG, Stock LA, Campos OF, Gomes AT, Zoccal R, Silva MR et al. Sistemas de produção de leite no Brasil. Juiz de Fora: Embrapa Gado de Leite; 2005. (Circular Técnica, 85).

3. Aguiar APA, Almeida BHPJF. Produção de leite a pasto: abordagem empresarial e técnica. Viçosa: Aprenda fácil; 1999.

4. Hoffman K, Muller LD, Fales SL, Holden LA. Quality evaluation and concentrate supplementation of rotational pasture grazed by lactating cows. J. Dairy Sci. 1993; 76:2651-63.

5. Vilela D, Alvim MJ, Campos OF, Resende JC. Produção de leite de vacas holandesas em confinamento ou em pastagem de coast-cross. R. Bras. Zoot. 1996; 25:1228-44.

6. Fontaneli RS. Forage systems for year-round grazing by lactating dairy cows [dissertation]. Gainesville: University of Florida; 1999.

7. Matos LM. Estratégias para redução do custo de produção de leite e garantia de sustentabilidade da atividade leiteira. In: Anais do Sul-Leite - 1 Simpósio sobre a Sustentabilidade da Pecuária Leiteira na Região Sul do Brasil, 2002; Maringá. Maringá: Universidade Estadual de Maringá; 2002.

8. Oliveira E. Opções de forrageiras de entressafra e inverno em sistema de integração lavoura e pecuária. In: Anais do $1^{\circ}$ Encontro de Integração Lavoura-Pecuária no Sul do Brasil, 2002; Pato Branco. Pato Branco; 2002. p. 327-64.

9. Moraes A. Produtividade animal e dinâmica de uma pastagem de pangola (Digitaria decumbens stent). Azevém (Lolium multiflorum Lam) e trevo branco (Trifolium repens L.), submetidas a diferentes pressões de pastejo [tese]. Porto Alegre; 1991.

10. Jank MS, Farina EMMQ, Galan VB. O agribusiness do Leite no Brasil. São Paulo: Milkbizz; 1999.

11. Provezano Gomes A. Impactos das transformações da produção de leite no número de produtores e requerimentos de mão-de-obra e capital [tese]. Viçosa: Universidade Federal de Viçosa; 1999.

12. Gil AC. Como elaborar projetos de pesquisa. São Paulo: Atlas; 2002. 